\title{
Biphasic Study to Characterize Agricultural Biogas Plants by High- Throughput 16S rRNA Gene Amplicon Sequencing and Microscopic Analysis
}

\author{
Irena Maus ${ }^{1}$, Yong Sung Kim ${ }^{2}$, Daniel Wibberg ${ }^{1}$, Yvonne Stolze $^{1}$, Sandra Off ${ }^{2}$, Sebastian Antonczyk ${ }^{2}$, \\ Alfred Pühler ${ }^{1}$, Paul Scherer ${ }^{2 \dagger}$, and Andreas Schlüter ${ }^{1+*}$ \\ ${ }^{1}$ Bielefeld University, Center for Biotechnology (CeBiTec), Genome Research and Systems Biology, 33615 Bielefeld, Germany \\ ${ }^{2}$ Hamburg University of Applied Sciences (HAW), Faculty Life Sciences / Research Center "Biomass Utilization Hamburg", Laboratory for \\ Applied Microbiology, 21033 Hamburg-Bergedorf, Germany
}

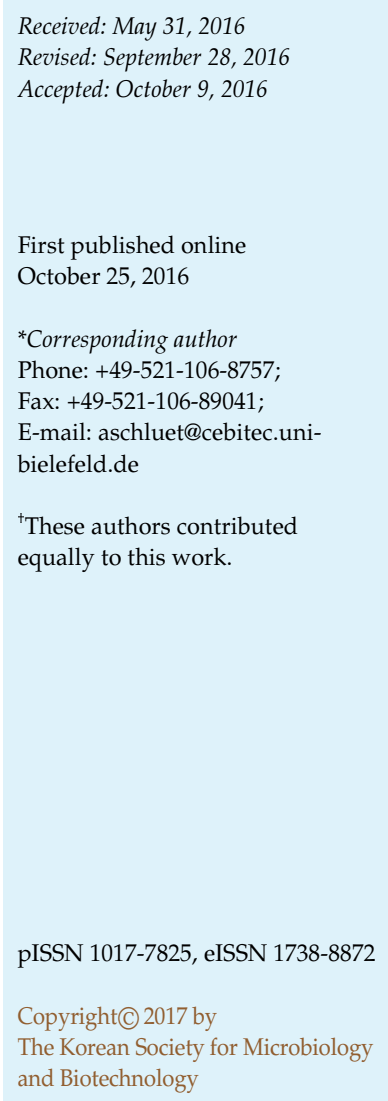

Process surveillance within agricultural biogas plants (BGPs) was concurrently studied by highthroughput 16S rRNA gene amplicon sequencing and an optimized quantitative microscopic fingerprinting (QMF) technique. In contrast to $16 \mathrm{~S}$ rRNA gene amplicons, digitalized microscopy is a rapid and cost-effective method that facilitates enumeration and morphological differentiation of the most significant groups of methanogens regarding their shape and characteristic autofluorescent factor 420. Moreover, the fluorescence signal mirrors cell vitality. In this study, four different BGPs were investigated. The results indicated stable process performance in the mesophilic BGPs and in the thermophilic reactor. Bacterial subcommunity characterization revealed significant differences between the four BGPs. Most remarkably, the genera Defluviitoga and Halocella dominated the thermophilic bacterial subcommunity, whereas members of another taxon, Syntrophaceticus, were found to be abundant in the mesophilic BGP. The domain Archaea was dominated by the genus Methanoculleus in all four BGPs, followed by Methanosaeta in BGP1 and BGP3. In contrast, Methanothermobacter members were highly abundant in the thermophilic BGP4. Furthermore, a high consistency between the sequencing approach and the QMF method was shown, especially for the thermophilic BGP. The differences elucidated that using this biphasic approach for mesophilic BGPs provided novel insights regarding disaggregated single cells of Methanosarcina and Methanosaeta species. Both dominated the archaeal subcommunity and replaced coccoid Methanoculleus members belonging to the same group of Methanomicrobiales that have been frequently observed in similar BGPs. This work demonstrates that combining QMF and 16S rRNA gene amplicon sequencing is a complementary strategy to describe archaeal community structures within biogas processes.

Keywords: Anaerobic digestion, taxonomic profile, archaeal morphology, microscopy

\section{Introduction}

Since accessible fossil fuel reservoirs are declining, there is the need to develop technologies for energy generation from renewable resources. Within the portfolio of renewable energies, production of fuels from biomass and agricultural waste has become an important branch of the energy industry, since green fuels can be stored, transported, and used for the production of electricity and heat [1-3]. Among the green fuels, biogas is generated during microbial degradation of plant biomass, animal manures, and other organic substrates under controlled anaerobic conditions. Complex consortia comprising Bacteria and Archaea generate energy-rich methane, starting from complex biomass-sourced biopolymers such as cellulose, xylan, starch, and other polymers. Hydrolysis, acidogenesis, and acetogenesis are 
carried out by Bacteria, whereas the last step, methanogenesis, is solely performed by methanogenic Archaea [4, 5].

Research on biogas-producing microbial communities, especially in agricultural biogas plants (BGPs), aims at elucidation of correlations and dependencies between process parameters and community compositions in order to optimize process stability and biogas output. Methanogenic Archaea are in the focus of many studies because they play a key role in the biogas cascade, methanogenesis, although their abundance and diversity are significantly lower than those of the Bacteria [6-9].

Over the last years, different approaches were developed to characterize archaeal communities. Some of the most commonly used methods for community profiling are (terminal) restriction fragment length polymorphism (TRFLP) analysis, qPCR, and, more commonly, 16S rRNA gene amplicon sequencing [6,10-13].

To enable a low-cost and less time-consuming method for quantification of methanogenic Archaea within fermenter samples, Kim et al. [14] used a fast quantitative microscopic fingerprinting (QMF) technique, which is suitable for biogas fermenters even with high solid contents from $6 \%$ up to $12 \%$. It is based on a previous image analysis method using the coenzyme $\mathrm{F}_{420}$-autofluorescence of methanogenic Archaea [15]. It includes morphology-based differences of archaeal taxa to enable their quantification and classification in a single liquid layer by image analysis of microscopic pictures. In their recent study, Kim et al. [14] compared the discrimination of living Archaea of biogas reactor samples into the orders Methanomicrobiales and Methanobacteriales and the families Methanosarcinaceae and Methanosaetaceae by means of a q-PCR approach and the QMF method. Both methods were shown to correlate, but also showed deviations [14].

In this study, three mesophilic BGPs and one thermophilic BGP were analyzed by applying the established method of high-throughput (HT) 16S rRNA gene amplicon sequencing in order to gain insights into the taxonomic compositions of their microbial communities. Moreover, the recently described QMF method was used to additionally quantify and classify methanogenic Archaea of the communities. Finally, both methods were compared to evaluate their respective strengths and weaknesses for archaeal community profiling of biogas reactor samples.

\section{Materials and Methods}

\section{Sampling at Four Agricultural Biogas Plants}

Three mesophilic and one thermophilic agricultural, full-scale BGPs located in North Rhine-Westphalia (Germany) were sampled in April 2015 to determine the structure and composition of their biogas-producing microbial communities. In the mesophilic BGP1, a dry fermentation technology with the addition of pig manure was performed (Table 1). However, the inoculum of dry fermentation of BGP1 was cow manure. Two mesophilic biogas plants, namely BGP2 and BGP3, and the thermophilic BGP4 were operated by applying the general continuous wet fermentation technology, with the addition of pig manure instead of cow manure in the case of BGP3 and BGP4. The description of the BGPs analyzed in this study was recently published $[6,16,17]$. Table 1 summarizes the process parameters, feeding details, process temperature, biogas yield, and methane content of the sampling time point for the different BGPs, as was recorded in the log sheets by the corresponding plant operators and by individual interviews. The produced gas was recalculated by the average value of the daily electricity (week before sampling) assuming an efficiency of $37 \%$ of the central heating and power plant (CHP of BGP2, 3, 4). Nevertheless, even though the latter measurement differ from the manufacturer (generally $40 \%$ ), it is in good agreement with data from our laboratory, obtained by direct gas measurement. For BGP1, a higher efficiency of $42 \%$ was taken, as a pilot injection gas engine was used as CHP. Typically, $1 \mathrm{~m}^{3}$ methane shall be equivalent to $9.97 \mathrm{~kW}$.

A sample volume of $1 \mathrm{~L}$ fermentation sludge was taken from the primary digester of each BGP in duplicates and filled into gastight bottles. Excess air was removed and the bottle was tightly closed with a screw cap. Subsequently, samples were immediately transported to the laboratory for community DNA extraction. In parallel, $500 \mathrm{ml}$ of each fermentation sample was used for chemical and microscopic analyses.

\section{Chemical Analysis of Fermentation Samples}

The biogas samples were centrifuged and the supernatant was acidified by addition of orthophosphoric acid to $\mathrm{pH}$ 2.0. Total volatile fatty acids, including alcohols, lactic acid, and phenyl acetic acid, were determined by a HP 5890 Series II GC with a flame ionization detector (FID) and a BP 21 bonded FFAP-fused silica column (length $25 \mathrm{~m}$, diameter $0.53 \mathrm{~mm}$, layer thickness $0.5 \mu \mathrm{m}$ ) operated at automatic mode and splitless. A $1 \mu \mathrm{l}$ volume of the acidified supernatant was injected into a liner filled with quartz glass wool. The temperature ranged between $70^{\circ} \mathrm{C}$ and $235^{\circ} \mathrm{C}$. Hydrogen $\left(\mathrm{H}_{2}\right)$ served as the carrier gas with a flow of $30 \mathrm{ml} / \mathrm{min}$, and an air-flow of $300 \mathrm{ml} / \mathrm{min}$ and makeup-flow (nitrogen) with $25 \mathrm{ml} / \mathrm{min}$ were set up. The total run time was $30 \mathrm{~min}$. Weekly calibration was performed using the commercial external standard Supelco, Nr. 46975-U from Sigma-Aldrich [18]. The volatile solid content was determined according to the standard guidelines, the VDI 4630 protocols [19]. $\mathrm{NH}_{4}-\mathrm{N}$ and phosphate $\left(\mathrm{PO}_{4}^{3-}\right)$ were measured by visible spectrometry with the Merck (Darmstadt) kit Nr. 1.00683 for Ammonium nitrogen $\left(\mathrm{NH}_{4}-\mathrm{N}\right)$ and the Macherey-Nagel (Dueren) Nanocolor test kit Nr. 91878 for phosphate. The $\mathrm{NH}_{4}-\mathrm{N}$ value was applied in an equation of Hansen et al. [20] to calculate the free ammonia concentration 
Table 1. Characteristics of the studied biogas plants (BGPs).

\begin{tabular}{|c|c|c|c|c|c|}
\hline \multirow{2}{*}{\multicolumn{2}{|c|}{ Sampling date }} & BGP1 & BGP2 & BGP3 & BGP4 \\
\hline & & 14.04 .2015 & 20.04 .2015 & 13.4 .2015 & 21.04 .2015 \\
\hline \multirow[t]{2}{*}{ Location of reactor } & latitude & $52.101596 \mathrm{~N}$ & $52.020388 \mathrm{~N}$ & $52.101596 \mathrm{~N}$ & $51.255499 \mathrm{~N}$ \\
\hline & longitude & $8.493483 \mathrm{O}$ & 8.5473630 & $8.493483 \mathrm{O}$ & $6.396524 \mathrm{E}$ \\
\hline \multicolumn{2}{|c|}{ Investigated reactor volume $\left[\mathrm{m}^{3}\right]$} & 1,557 & 1,400 & 2,041 & $115 \times 3^{\mathrm{a}}$ \\
\hline \multicolumn{2}{|l|}{ Type of reactor } & $\begin{array}{c}\text { CSTR, } \\
\text { dry fermentation }\end{array}$ & $\begin{array}{c}\text { CSTR, } \\
\text { wet fermentation }\end{array}$ & $\begin{array}{c}\text { CSTR, } \\
\text { wet fermentation }\end{array}$ & $\begin{array}{l}\text { Liquid pump/ } \\
\text { wet fermentation }\end{array}$ \\
\hline \multicolumn{2}{|c|}{ Fed substrates as wet weigh ${ }^{\mathrm{a}, \mathrm{b}}[\%]$} & $\begin{array}{c}\text { Maize }(55.4 \%), \\
\text { sugar beet }(7.6 \%), \\
\text { potato }(5.2 \%), \\
\text { cattle solid manure }(31.8 \%)\end{array}$ & $\begin{array}{c}\text { Maize }(61.9 \%), \text { rye } \\
(30.5 \%) \text {, grass }(7.6 \%)\end{array}$ & $\begin{array}{c}\text { Maize }(66.5 \%), \\
\text { pig manure }(33.5 \%)\end{array}$ & $\begin{array}{c}\text { Maize }(64 \%), \\
\text { pig manure }(32 \%), \\
\text { grass }(4 \%)\end{array}$ \\
\hline \multicolumn{2}{|c|}{ Daily total input as wet mass ${ }^{\mathrm{a}}[\mathrm{kg} / \mathrm{d}]$} & 38,900 & 24,500 & 36,500 & 16,500 \\
\hline \multicolumn{2}{|c|}{ Daily total input as dry mass ${ }^{a, b}[\mathrm{~kg} / \mathrm{d}]$} & 11,430 & 5,584 & 8,200 & 3,779 \\
\hline \multicolumn{2}{|c|}{$\begin{array}{l}\text { Daily organic loading rate } \\
{\left[\mathrm{kg} \mathrm{oDM} / \mathrm{m}^{3} / \mathrm{d}\right]}\end{array}$} & 7.3 & 4.0 & 4.0 & 8.0 \\
\hline \multicolumn{2}{|c|}{ Hydraulic retention time [d] } & 40 & 57 & 56 & 28 \\
\hline \multicolumn{2}{|c|}{ Daily electricity production [kWh/d] } & 12,788 & 5,914 & 10,094 & 4,248 \\
\hline \multicolumn{2}{|l|}{ Recirculation applied } & No & No & No & Yes \\
\hline \multicolumn{2}{|c|}{ Temperature of stage $\left[{ }^{\circ} \mathrm{C}\right]$} & 39 & 40 & 40.4 & 56.2 \\
\hline \multicolumn{2}{|c|}{ Biogas yield [1/kg oDM] } & 554.0 & 548.1 & 633.5 & 631.8 \\
\hline \multicolumn{2}{|c|}{ Methane yield [1/kg oDM] } & 292.5 & 289.4 & 333.5 & 332.9 \\
\hline \multicolumn{2}{|c|}{ Methane content of biogas [vol \%] } & 52.8 & 52.8 & 52.6 & 52.7 \\
\hline
\end{tabular}

${ }^{a}$ BGP4 consists of three cylindrical digesters of $14 \mathrm{~m}$ height and $3 \mathrm{~m}$ in diameter. These fermenters operate in parallel and are connected to each other. The daily input and electricity were related to the sum of the 3 digesters.

${ }^{\mathrm{b}} \mathrm{TS} / \mathrm{oDM}$ of the substrates in percent: Maize 33/31.35; Sugar beet 23/20.7; Potato 22/20.68; Cattle solid manure 25/21.25; Pig manure 6/4.8; Rye 33/31.35; Grass 35/ 31.5. The KTBL tables [22] were used to transfer the wet weight of fed substrates into dry matter and organic dry matter.

$\left(\mathrm{NH}_{3}-\mathrm{N}\right)$. Alkalinity was determined according to the Standard Methods for the Examination of Water and Wastewater (APHA, 1992) [21]. For conductivity estimations, the WTW instrument Cond 3110 (Technische Werkstatten Weilheim) with the measuring cell TetraCon 325 was used. The KTBL tables [22] were used to transfer the wet weight of fed substrates into dry matter and organic dry matter (oDM).

\section{Extraction of Total Microbial DNA from Fermentation Samples}

Total community DNA was extracted using the FastDNA SPIN Kit for Soil (MP Biomedicals, USA) according to the manufacturer's instructions. Mechanical cell disruption was performed using the Precellys 24 homogenizer (Peqlab, Germany) two times at 6,500 rpm for $30 \mathrm{sec}$. Finally, the samples were purified using the Genomic DNA Clean \& Concentrator Kit (Zymo Research, USA) to recover pure DNA. For each sample, DNA from two subsamples was extracted and used as template for construction of $16 \mathrm{~S}$ rRNA gene amplicon libraries.

Microbial Community Structure Analysis by HT 16S rRNA Gene Amplicon Sequencing

Biogas-producing microbial communities of the four agricultural fermenters were taxonomically characterized by HT 16S rRNA gene amplicon sequencing, applying the $16 \mathrm{~S}$ metagenomic sequencing library preparation protocol (Illumina Inc., 2014) for sequence library construction. To amplify the third and fourth variable regions (V3, V4) of the 16S rRNA gene, the primers Pro341F (5'CCTACGGGNBGCASCAG-3') and Pro805R (5'-GACTACNVG GGTATCTAATCC-3') [23] covering the domains Bacteria and Archaea were used for the first PCR round. These primers were recommended as "universal" ones and were successfully applied in the project addressing community profiling of pig fecal samples [23], a common substrate for biomethanation. After purification of amplicons with Agencourt AMPureXP beads (Beckman Coulter Genomics Inc.), only amplicons featuring the correct length of approximately $460 \mathrm{bp}$ were obtained. Finally, Multiplex Identifier (MID) tags as well as sequencing adaptors were attached to the amplicons in a second PCR using the Nextera XT Index Kit (Illumina Inc.). The qualitative and quantitative analyses of the generated amplicons were performed using the Agilent 2100 Bioanalyzer system (Agilent Inc.). Constructed 16S rRNA gene amplicon libraries were pooled in equimolar amounts and diluted for the sequencing procedure to $2 \mathrm{~nm}$. Obtained amplicon libraries were sequenced on the Illumina MiSeq system (Illumina, USA) 
using the paired-end protocol.

For amplicon processing, a pipeline including FLASH [24], USEARCH 8.0 [25], UPARSE [26], and the RDP classifier [27] was used as described recently [10,28]. In the first filtering step, all sequences that were not merged by FLASH with default settings were removed. In the second step, operational taxonomic units (OTUs) were defined at $97 \%$ sequence similarity required for the identification at the species level applying the program USEARCH. Furthermore, sequences with $>1$ Ns (ambiguous bases) in the read and expected errors $>0.5$ were also discarded. The MID tags and primer sequences were removed, allowing 0 and 2 mismatches, respectively. The software package UPARSE was applied for denoising and chimera detection. Processed OTUs were taxonomically classified using the RDP classifier 2.7 in 165 modus [27]. Only assignments featuring a confidence value of at least 0.8 (phylum rank) were considered. Finally, raw sequences were mapped on the OTU sequences to get quantitative assignments.

The strain Defluviitoga tunisiensis L3 originates from the thermophilic BGP analyzed (BGP4) as described previously by our group [16, 29]. Furthermore, this study also showed that Defluviitoga members are highly abundant in the corresponding fermenter. Owing to the lack of Defluviitoga 16S rRNA gene sequences in the RDB database (https://rdp.cme.msu.edu/) when the analysis was performed, additional investigation of all Thermotogae sequences from BGP4 was done. For this, the 16S rRNA gene sequence of the strain Defluviitoga tunisiensis L3 [16] was compared against the 16S rRNA gene amplicon sequences applying BLASTn (https:// blast.ncbi.nlm.nih.gov/Blast.cgi?PAGE_TYPE=BlastSearch) with $97 \%$ sequence identity and an e-value of $1 \times 10^{-10}$.

The ClustVis [30] and metagenomeSeq tools [31] were used to detect differentially abundant features in the datasets analyzed using Principal Component Analysis (PCA) as described recently [30]. Furthermore, to gain an overview on the biodiversity of the studied microbial communities, the Shannon index was computed based on 16S rRNA fragments classified on rank genus as described previously [8].

Raw sequencing data are available in the EBI/NCBI/DDBJ database under the sample accession number ERS1327727.

\section{Microscopy of Biogas Microbial Communities Including Image Analysis}

Leica DM6000B fluorescence microscope with a motorized and software-controlled three axes cross table and a Leica DFC365FX camera were used for microbial image analyses. Depending on the volatile solids content, the samples were diluted 30 times or 60 times for analysis of methanogens and total cells, respectively. An artificial disaggregation was not necessary to generate single cells. The stain SYBR-Green I (Life Technologies Darmstadt; 10,000x concentrate, S7563) was used for the analysis of total cells. For each sample, approximately 20 images in different positions were taken in succession under 400-fold magnification in order to increase statistical insurance. From those pictures, an average value was then obtained. Two different filter cubes, Leica CFP for excitation 426-446 nm and emission 460-500 nm, and Leica L5 for excitation $460-500 \mathrm{~nm}$ and emission $512-542 \mathrm{~nm}$, were used for detection of methanogens and total cells, respectively. For automatic image analysis required for quantification and classification of microbes, the commercially available image analysis software Image Pro 7 (MediaCybernetics, USA) was applied. The detailed method description can be found in a previously published paper [14, 15].

\section{Results}

\section{Chemical Analyses of the Fermenter Samples of the Biogas Plants Studied}

To evaluate the process performance of the biogas plants at the time of sampling, fermentation samples were analyzed for their chemical parameters (Table 2). All of the investigated fermenters had similar values of conductivity between 15 to $20 \mathrm{mS} / \mathrm{cm}$ and a low dissolved phosphate content, between 100 and $240 \mathrm{mg} / \mathrm{l}$. The total concentrations of short-chained volatile fatty acids (VFA) of the four biogas plants were also relatively low, varying between 40 and $140 \mathrm{mg} / 1$ in BGP1 to BGP3. Only BGP4 had a higher concentration of $784 \mathrm{mg} / \mathrm{l}$. The accumulation of VFA in biogas plants (i.e. above $1,500 \mathrm{mg} / \mathrm{l}$ ) can be associated with the inhibition of methanogens [21]. Concentrations below $1,000 \mathrm{mg} / 1$ are regarded as non-critical [21]. This was the case for all investigated reactors. The alkalinity of the three fermenters, BGP1-3, had stable buffering capacity of around, or higher than, $10,000 \mathrm{mg} \mathrm{CaCO}_{3} / 1$. Ammonia concentrations $\left(\mathrm{NH}_{4}^{+}\right)$ranged between 1,600 and 3,000 mg/1 in the analyzed fermenters. Free ammonia $\left(\mathrm{NH}_{3}\right)$ is recognized as a potential inhibitory factor of biogas processes, and the highest content was found in BGP4 at $435 \mathrm{mg} / \mathrm{l}$. This high $\mathrm{NH}_{3}$ concentration was due to the high ammonium content and the temperature of $56^{\circ} \mathrm{C}$, which was later reduced to $53^{\circ} \mathrm{C}$. Furthermore, the experimental results revealed slightly increased contents of acetic, propionic, isobutyric, butyric, isovaleric, and valeric acids in BGP4. BGP4 also had the highest content of propionic acid (229 mg/l), which may indicate stress conditions [32]; however, this was lower than the critical process hindering concentration of $500 \mathrm{mg} / 1$ [32]. The relatively high organic loading rate (OLR) of $8 \mathrm{~kg} \mathrm{oDM} / \mathrm{m}^{3} / \mathrm{d}$ and the short hydraulic retention time (HRT) of $28 \mathrm{~d}$ of the thermophilic BGP4 is in line with the increased VFA levels observed. In contrast, BGP1-3 were all operated with moderate OLRs of $7.3,4.0$, and $4.0 \mathrm{~kg} \mathrm{oDM} / \mathrm{m}^{3} / \mathrm{d}$ and also moderate HRTs of 40, 57, and $56 \mathrm{~d}$, respectively. Alcoholic metabolites within the four fermenters were negligible $(<100 \mathrm{mg} / \mathrm{l})$. BGP1 and 
Table 2. Chemical analysis of fermenter samples from biogas plants BGP1 to BGP4.

\begin{tabular}{|c|c|c|c|c|}
\hline & BGP1 & BGP2 & BGP3 & BGP4 \\
\hline $\mathrm{pH}$ value & 7.80 & 7.97 & 7.80 & 7.97 \\
\hline TS/VS [\%] & $12.83 / 6.99$ & $9.77 / 6.76$ & $7.42 / 5.68$ & $9.50 / 7.48$ \\
\hline Conductivity $[\mathrm{mS} / \mathrm{cm}]$ & $15.1\left(19.2^{\circ} \mathrm{C}\right)=8,714$ & $18 \cdot 2\left(12 \cdot 8^{\circ} \mathrm{C}\right)=10,793$ & $20.5\left(15.3^{\circ} \mathrm{C}\right)=12,157$ & $19.0\left(10.8^{\circ} \mathrm{C}\right)=11,267$ \\
\hline Alkalinity $\left[\mathrm{mgCaCO}_{3} / 1\right]$ & 11,780 & 14,330 & 14,180 & 9,790 \\
\hline Ammonium $\left[\mathrm{NH}_{4}-\mathrm{N} \mathrm{mg} / \mathrm{l}\right]$ & 1,658 & 2,498 & 3,055 & 1,677 \\
\hline Ammonia $\left[\mathrm{NH}_{3}-\mathrm{N} \mathrm{mg} / \mathrm{l}\right]$ & 125 & 269 & 231 & 435 \\
\hline \multirow[t]{2}{*}{ Phosphate [mg/l] } & 97 & 165 & 153 & 240 \\
\hline & {$[\mathrm{mg} / \mathrm{l}]$} & {$[\mathrm{mg} / \mathrm{l}]$} & {$[\mathrm{mg} / \mathrm{l}]$} & {$[\mathrm{mg} / \mathrm{l}]$} \\
\hline Methanol & 3.0 & 3.0 & 4.0 & 3.0 \\
\hline Ethanol & 3.6 & 6.6 & 3.6 & 12.0 \\
\hline Propanol & 1.0 & 1.0 & 1.0 & 1.5 \\
\hline Butanol & $<1.0$ & $<1.0$ & $<1.0$ & $<1.0$ \\
\hline Acetic acid & 52.2 & 129.1 & 40.9 & 474.2 \\
\hline Propionic acid & 3.7 & 6.6 & 3.2 & 229.6 \\
\hline Isobutyl acid & $<1.0$ & 1.7 & $<1.0$ & 43.5 \\
\hline Butyl acid & 1.0 & 1.0 & $<1.0$ & 9.6 \\
\hline Isovaleric acid & $<1.0$ & 2.0 & $<1.0$ & 24.5 \\
\hline Valeric acid & $<1.0$ & 1.0 & $<1.0$ & 2.7 \\
\hline Total alcohol (ROH) & 7.6 & 10.6 & 8.6 & 16.5 \\
\hline Total VFA & 56.9 & 141.4 & 44.1 & 784.0 \\
\hline VFA + alcohol & 64.5 & 152.0 & 52.7 & 800.5 \\
\hline VFA/alkalinity by GC & $<0.01$ & 0.01 & $<0.01$ & 0.08 \\
\hline
\end{tabular}

BGP2 exhibited a high biogas and methane yield ranging between 290 and $292 \mathrm{~m}^{3} / \mathrm{kg}$ oDM. BGP3 and BGP4 had $10 \%$ higher specific gas yields (Table 1), indicating high performance.

\section{Characterization of Bacterial Subcommunities Residing in Four Agricultural Biogas Plants with HT 16S rRNA Gene Amplicon Sequencing}

To analyze the composition of the microbial communities prevailing in three mesophilic and one thermophilic production-scale BGP, HT 16S rRNA gene amplicon sequencing was performed using the Illumina MiSeq system. The taxonomic community structure was determined using the UPARSE pipeline [26]. Statistics of the obtained, processed, and classified 16S rRNA gene sequences are provided in Table 3. Taxonomic profiles of the domains Bacteria and Archaea (combined results of two independent technical replicates) are visualized as bar charts in Fig. 1, which represent the relative abundances of classified reads on class, family, and genus levels.

Taxonomic classification of the biogas microbial communities resulted in two superkingdoms, with $92 \%$ (BGP1 and BGP4), 95\% (BGP3), and 96\% (BGP2) of all classified sequences assigned to the domain Bacteria and $4 \%$ (BGP2), 5\% (BGP3), and 8\% (BGP1 and BGP4) archaeal sequences. At higher taxonomic ranks, the mesophilic bacterial subcommunities appeared to be very similar. They mainly comprise the phyla Firmicutes (53\% in BGP1, $45 \%$ in BGP2, and $42 \%$ in BGP3), followed by Bacteroidetes (13\% in BGP1, 16\% in BGP2, and 19\% in BGP3), Spirochaetes ( $1 \%$ in BGP1, $\%$ in BGP2, and $4 \%$ in BGP3), and Tenericutes $(0.7 \%$ in BGP1, $2 \%$ in BGP2, and $2 \%$ in BGP3). However, the taxonomic profile of BGP1 differs compared with the other two mesophilic BGPs regarding the occurrence of the phyla Actinobacteria (1\%) and Proteobacteria (1\%). In BGP3, sequences assigned to the phyla Synergistetes (1\%) and Fusobacteria (2\%) were observed. In addition to the high prevalence of Firmicutes (43\%) and Bacteroidetes members ( $2 \%$ ) in the taxonomic profile of the thermophilic BGP4, $42 \%$ of the classified sequences were assigned to the phylum Thermotogae. The abundance of the phylum Bacteriodetes was with $2 \%$ significantly lower in the thermophilic biogas 
Table 3. Statistics of raw, filtered, and classified 16S rRNA gene amplicon sequences obtained for four biogas plants (BGP1 to BGP4).

\begin{tabular}{ccccccc}
\hline \multicolumn{2}{c}{ Biogas plants } & No. of obtained raw sequences & No. of sequences after filtering & OTUs & OTUs $^{\mathrm{b}}$ & Classified sequences $^{\mathrm{a}}$ \\
\hline \multirow{2}{*}{ BGP1 } & Replicate 1 & 362,433 & 318,874 & 706 & 403 & 290,745 \\
& Replicate 2 & 71,017 & 62,651 & 323 & 321 & 53,998 \\
\multirow{2}{*}{ BGP2 } & Replicate 1 & 105,902 & 92,842 & 315 & 295 & 83,918 \\
& Replicate 2 & 140,836 & 123,987 & 345 & 301 & 112,871 \\
\multirow{2}{*}{ BGP3 } & Replicate 1 & 75,412 & 67,508 & 272 & 270 & 60,919 \\
& Replicate 2 & 99,551 & 86,279 & 277 & 267 & 77,583 \\
BGP4 & Replicate 1 & 186,295 & 166,493 & 118 & 92 & 156,290 \\
& Replicate 2 & 84,477 & 74,516 & 85 & 82 & 68,666 \\
\hline
\end{tabular}

${ }^{a}$ Filtering of sequences was done according to the following criteria: reads with low quality scores, chimera, and duplicates were discarded (as specified in the Materials and Methods section).

${ }^{\mathrm{b}}$ Additional OTU-clustering applying normalization of the $16 \mathrm{~S}$ rRNA gene amplicon-derived sequences to an equal sample size was performed to compare obtained OTUs between the datasets. The 61,000 randomly selected sequences (sub-sample) were extracted from each dataset using the program Seqtk [33].

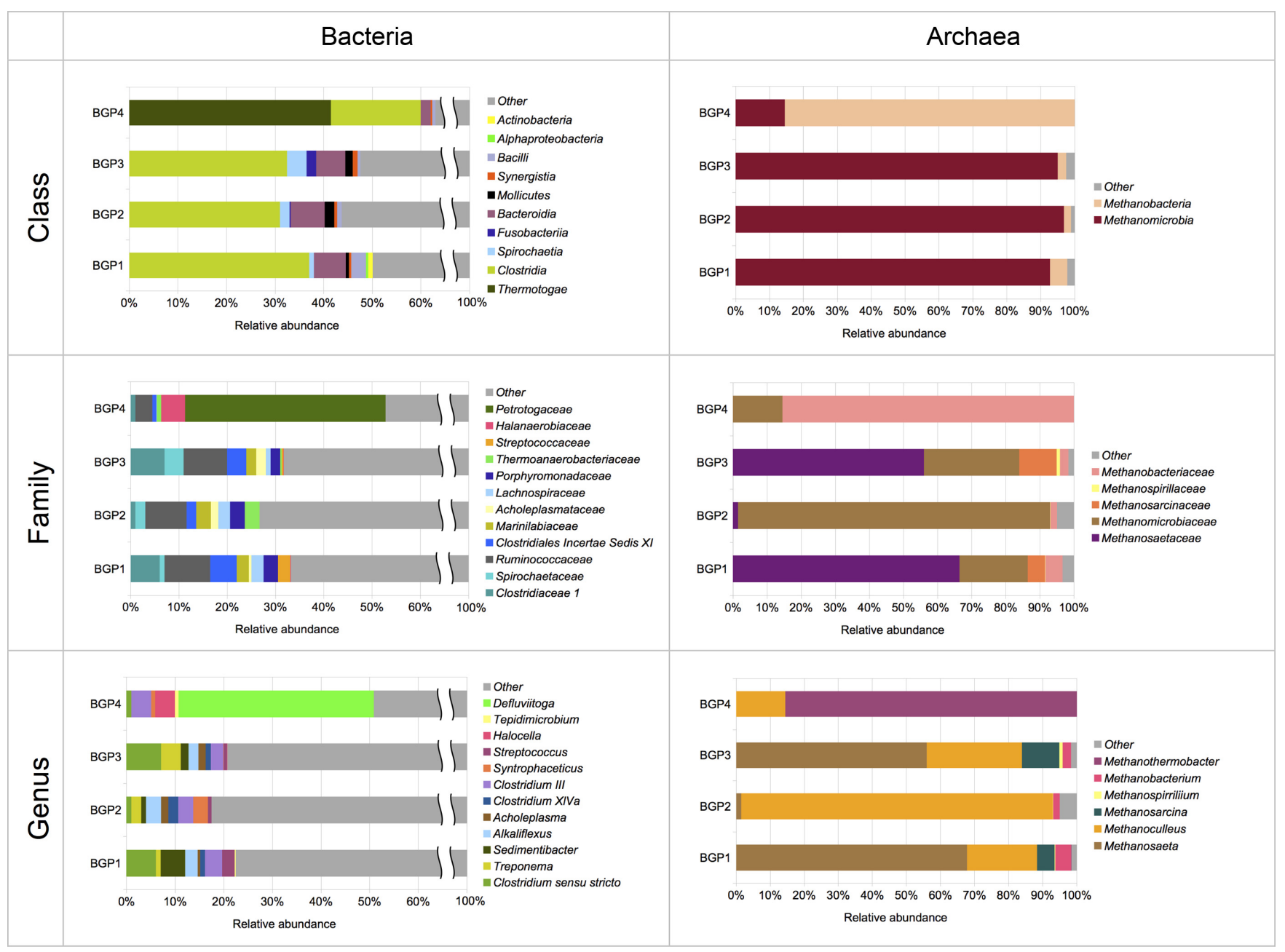

Fig. 1. Taxonomic profiling of microbial communities residing in four biogas plants based on high-throughput $16 \mathrm{~S}$ rRNA gene amplicon sequencing.

Relative abundances of the most abundant classes, families, and genera of bacterial (left) and archaeal (right) subcommunities are shown. 
reactor than in BGP1, 2, and 3 (13\% to $19 \%)$.

The most abundant bacterial classes in the analyzed communities were Clostridia (between 19\% in BGP4 and $37 \%$ in BGP1) and Bacteroidia (between $2 \%$ in BGP4 and $7 \%$ in BGP1 and BGP2). Comparison of the taxonomic profiles on the family level disclosed a few distinct taxa characterizing particular samples. For BGP1, 3\% of the sequences were assigned to the family Streptococcaceae, whereas in BGP2, 3\% of the sequences originating from Thermoanaerobacteriaceae members could be classified. In contrast to the mesophilic BGPs, the thermophilic BGP4 showed high amounts of sequences belonging to the families Petrotogaceae (42\%) and Halanaerobiaceae (5\%). Halocella (4\%, Halanaerobiaceae), Clostridium family III (4\%, Ruminococcaceae) and Tepidimicrobium (0.8\%, Clostridiales Incertae Sedis $\mathrm{XI}$ ) were the prominent genera in this bacterial subcommunity. The most abundant genera in the mesophilic fermenters were Clostridium sensu stricto $(6 \%$ in BGP1, $1 \%$ in BGP2, and $7 \%$ in BGP3), Treponema (1\% in BGP1, 2\% in BGP2, and 4\% in BGP3), and Alkaliflexus (3\% in BGP1 and BGP2 and 2\% in BGP3). The genus Syntrophaceticus (3\%) was observed only in the mesophilic BGP2, and the thermophilic genera Defluviitoga (40\%) and Halocella (4\%) were only detected in the thermophilic BGP4.

Finally, to compare the microbial community structures of the analyzed BGPs, PCA with the program ClustVis [30] was conducted. Results for each independent technical replicate are shown in Fig. 2. As expected, PCA revealed close clustering of samples representing technical replicates, whereas samples from the mesophilic and thermophilic BGPs were clearly separated from each other, indicating significant differences concerning their microbial community compositions. Furthermore, clustering of the mesophilic samples from BGP2 and BGP3 within the PCA plot was observed. This is most likely due to the diversity of the BGP1 microbiome, as indicated by the number of OTUs identified (Table 3) for this reactor (403 and 321 for BGP1 vs. 267 to 301 for BGP2 and 3). It is assumed that the microbial diversity within BGP1 was introduced by the heterogeneity of the fed substrate (see Table 1: maize silage, sugar beet, potato, and cattle manure in BGP1), in comparison with the less heterogeneous substrates used for BGP2 and BGP3 (maize silage, rye, and grass in BGP2, and maize silage and pig manure in BGP3).

Moreover, the thermophilic fermenter contained a less diverse microbial community compared with the mesophilic fermenters. The Shannon index values for the mesophilic biogas communities ranged from 4.3 to 4.4 in comparison with the thermophilic microbiome for which a value of 2.5

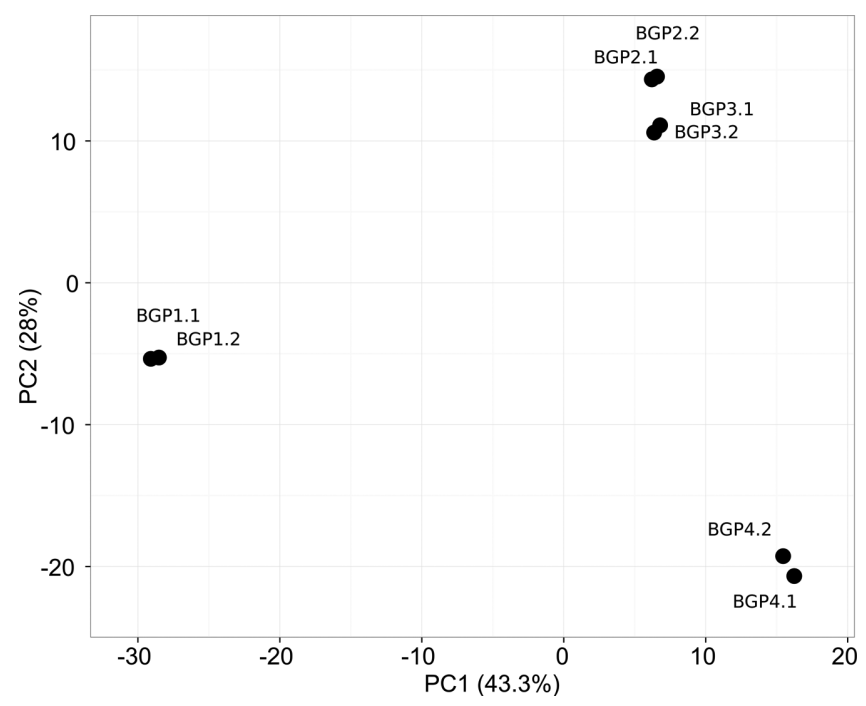

Fig. 2. Principal component analysis plot of $16 \mathrm{~S}$ rRNA gene amplicon sequencing data obtained from biogas microbial communities analyzed.

The ClustVis program [30] was applied to detect differentially abundant features in samples representing three mesophilic microbial communities (BGP1, BGP2, and BGP3) and one thermophilic microbiome (BGP4). Two independent technical replicates for each BGP sample are shown (e.g., BGP1.1, first replicate of the BGP1 sample). The variance (\%) is reported for each principal component (PC).

was calculated. This was also evident from the number of identified OTUs given in Table 3 (82 to 92 for BGP4 vs. 267 to 403 for the mesophilic BGP1, 2, and 3). Moreover, on lower taxonomic levels, the compositions of the mesophilic communities also differed significantly compared with the thermophilic community. Among the mesophilic biogas plants, BGP1 was fed with the most heterogeneous substrate and exhibited high percentages of the genera Streptococcus and Sedimentibacter, whereas BGP2 only received plant biomass as substrate, without co-feeding of manure, and its community structure differed regarding abundances of specific taxa compared with the other mesophilic BGPs. For example, the genera Syntrophoaceticus and Methanoculleus were only identified in BGP2 (Fig. 1). Therefore, differences between the communities of the mesophilic BGPs may be due to the substrate diversity and/or addition of manure.

Classification of the Methanogenic Subcommunity within the Thermophilic and Mesophilic BGPs Applying 16S rRNA Gene Amplicon Sequencing

Taxonomic classification of the archaeal subcommunity (Fig. 1) using HT 16S rRNA gene amplicon sequencing revealed that $4 \%$ to $8 \%$ of all classified $16 \mathrm{~S}$ rRNA gene sequences were assigned to the superkingdom Archaea. 
Members of the phylum Euryarchaeota were shown to be abundant (with $100 \%$ of all archaeal sequences assigned to this phylum). Members of the class Methanomicrobia (92\% in BGP1, 93\% in BGP2, 96\% in BGP3, and 15\% in BGP4) dominated the methanogenic subcommunities, followed by Methanobacteria (5\% in BGP1, 2\% in BGP2, 3\% in BGP3, and $85 \%$ in BGP4), respectively. Among the archaeal sequences obtained for BGP1, BGP2, and BGP3, 1\%, 3\%, and 1\% were classified as belonging to the class Thermoplasmata, respectively. Species of the class Thermoplasmata are known to represent non-methanogenic, acidophilic Archaea [34] typically growing at $\mathrm{pH}$ values below 2 . The family Methanomicrobiaceae represented $20 \%$ of all archaeal reads in BGP1, 92\% in BGP2, $28 \%$ in BGP3, and $15 \%$ in BGP4. Within the class Methanomicrobia, the family Methanosaetacea accounted for $67 \%$ in BGP1, $2 \%$ in BGP2, and $56 \%$ in BGP3. In BGP1 and BGP3, sequences assigned to the family Methanosarcinaceae were present ( $5 \%$ and $11 \%$, respectively). High amounts of sequences belonging to the family Methanobacteriaceae (86\%) were found in the thermophilic BGP4. The genus Methanoculleus was highly abundant in all four methanogenic subcommunities (20\% in BGP1, 92\% in BGP2, $28 \%$ in BGP3, and $15 \%$ in BGP4). Methanosaeta sequences were detected for the mesophilic BGP1 (67\%) and BGP3 (56\%), and in addition, the genus Methanosarcina was only detected in BGP1 $(6 \%)$ and BGP3 (11\%). The thermophilic BGP4 was clearly dominated by methanogens, with the genus Methanothermobacter (86\%) being present only in this reactor.

\section{Morphological Classification of Methanogenic Archaea by Microscopy and Image Analysis}

DNA isolation from archaeal organisms is a challenging task [35] owing to the presence of cell wall glycoproteins, which cause difficulties in cell disruption of some archaeal members such as Methanothermobacter [36]. Therefore, archaeal subcommunity profiles determined by HT sequencing of $16 \mathrm{~S}$ rRNA gene amplicons were additionally evaluated by implementing the QMF method in order to provide further insights into their composition.

Quantification of active methanogenic cells was achieved by exploiting the characteristic autofluorescence based on coenzyme $\mathrm{F}_{420}$ (Tables 4 and 5, Figs. 3 and 4). A similar composition of methanogens was observed in BGP1 and BGP3. In BGP1, 8.3\% of all microbial cells were assigned to the methanogens, whereas in BGP3, $6 \%$ of methanogens were identified. In BGP1, a fraction of $73 \%$ was identified as coccoid-type methanogens (Fig. 4A) being 1 to $2 \mu \mathrm{m}$ in length, whereas $32 \%$ of them were significantly smaller (approx. 0.5 to $1 \mu \mathrm{m}$ ). In BGP3 (Fig. 4C), coccoid-type methanogens accounted for $60 \%$ of the methanogenic fraction (in total $6.1 \%$ ). Furthermore, a relatively high percentage (79\% or $2.0 \%$ of $6.1 \%$ in total) of rod-type methanogens ranging from $>1$ to $<6 \mu \mathrm{m}$ was also found in BGP3. The morphotypes of methanogens in BGP1 and BGP3 were similar but the fraction of the coccoid-type methanogens was slightly higher in BGP1 compared with BGP3.

In BGP2 (Fig. 4B), methanogenic Archaea comprised 14\% of all cells, in which the coccoid-type methanogens were dominant $(83 \%)$. The coccoid-type methanogens were between 1 and $2 \mu \mathrm{m}$ in length and represent the largest share of this size range among the four biogas plants. The rod-type methanogens (87\%) were mostly between 2 and $6 \mu \mathrm{m}(87 \%$ of the $1.7 \%$ fraction) confirming results previously obtained for other BGPs [14].

The highest number of methanogens and the highest share of methanogens were found in BGP2 with $4.88 \mathrm{E}+9$ cells per milliliter (Table 4 and Fig. 4). The highest fluorescence intensity of methanogens (79\%) was also found in BGP2, which received substrates containing higher amounts of biodegradable organics like maize, rye, and grass compared with the other fermenters that were also fed with pig manure.

Methanogens identified in BGP4 (Fig. 4D) featured a share of $10 \%$ of the total cell counts. The rod-type methanogens (80\%) were dominant, exhibiting unusually curled rod shapes (Figs. 3C and 3D), whereas only 20\% of the methanogens featured coccoid-type cells. Curled rods can be found

Table 4. Cell counts and fluorescence intensity analyzed by fluorescence microscopy applying an image analysis software.

\begin{tabular}{|c|c|c|c|c|c|c|c|c|}
\hline & \multicolumn{2}{|c|}{ BGP1 } & \multicolumn{2}{|c|}{ BGP2 } & \multicolumn{2}{|c|}{ BGP3 } & \multicolumn{2}{|c|}{ BGP4 } \\
\hline & Value & $\mathrm{SD}^{\mathrm{a}}$ & Value & SD & Value & SD & Value & SD \\
\hline Total cells, $\mathrm{N} / \mathrm{ml}$ & $3.26 \mathrm{E}+10$ & $18 \%$ & $3.52 \mathrm{E}+10$ & $11 \%$ & $4.85 \mathrm{E}+10$ & $11 \%$ & $3.72 \mathrm{E}+10$ & $18 \%$ \\
\hline Methanogenic cells, $\mathrm{N} / \mathrm{ml}$ & $2.72 \mathrm{E}+09$ & $17 \%$ & $4.88 \mathrm{E}+09$ & $19 \%$ & $2.95 \mathrm{E}+09$ & - & $3.70 \mathrm{E}+09$ & $10 \%$ \\
\hline Ratio of methanogens to the total cells [\%] & 8.3 & - & 13.8 & - & 6.1 & 7 & 10.0 & - \\
\hline Methanogenic fluorescence intensity [\%] & 68.5 & 5 & 78.5 & 4 & 68.8 & 9 & 38.0 & 10 \\
\hline
\end{tabular}

${ }^{\mathrm{a}} \mathrm{SD}$ refers to the standard deviation calculated from 20 images $(n=20)$. 
Table 5. Morphological classification including relative ratios to total cells as well as to the category of methanogenic or nonmethanogenic cells.

\begin{tabular}{|c|c|c|c|c|c|c|c|c|c|c|c|c|}
\hline & & BGP1 & & & BGP2 & & & BGP3 & & & BGP4 & \\
\hline & $\begin{array}{c}\text { Cells/ } \\
\mathrm{ml}\end{array}$ & $\begin{array}{l}\text { Category } \\
\text { ratio [\%] }\end{array}$ & $\begin{array}{c}\text { Total } \\
\text { ratio } \\
{[\%]}\end{array}$ & $\begin{array}{c}\text { Cells/ } \\
\mathrm{ml}\end{array}$ & $\begin{array}{l}\text { Category } \\
\text { ratio [\%] }\end{array}$ & $\begin{array}{c}\text { Total } \\
\text { ratio } \\
{[\%]}\end{array}$ & $\begin{array}{c}\text { Cells/ } \\
\mathrm{ml}\end{array}$ & $\begin{array}{l}\text { Category } \\
\text { ratio [\%] }\end{array}$ & $\begin{array}{c}\text { Total } \\
\text { ratio } \\
{[\%]}\end{array}$ & $\begin{array}{c}\text { Cells/ } \\
\mathrm{ml}\end{array}$ & $\begin{array}{l}\text { Category } \\
\text { ratio [\%] }\end{array}$ & $\begin{array}{c}\text { Total } \\
\text { ratio } \\
{[\%]}\end{array}$ \\
\hline \multicolumn{13}{|l|}{$\begin{array}{l}\text { Methanogenic } \\
\text { cells }\end{array}$} \\
\hline $\begin{array}{l}\text { Coccoid type } \\
(\text { cocci }<1 \mu \mathrm{m})^{b}\end{array}$ & $2.0 \mathrm{E}+09$ & $\begin{array}{l}73.1 \\
(32)\end{array}$ & 6.1 & $4.3 \mathrm{E}+09$ & $\begin{array}{l}87.5 \\
(14)\end{array}$ & 12.1 & $1.8 \mathrm{E}+09$ & $\begin{array}{l}60.5 \\
(18)\end{array}$ & 3.7 & $6.5 \mathrm{E}+08$ & $\begin{array}{l}17.5 \\
(6)\end{array}$ & 1.7 \\
\hline Rod type & $7.3 \mathrm{E}+08$ & 26.9 & 2.2 & $6.1 \mathrm{E}+08$ & 12.5 & 1.7 & $1.2 \mathrm{E}+09$ & 39.5 & 2.4 & $3.0 \mathrm{E}+09$ & 80.3 & 8.0 \\
\hline $\begin{array}{l}\text { Multicellular } \\
\text { packets }\end{array}$ & n. d. ${ }^{a}$ & n. d. & n. d. & n. d. & n. d. & n. d. & n. d. & n. d. & n. d. & n. d. & n. d. & n. d. \\
\hline \multicolumn{13}{|l|}{$\begin{array}{l}\text { Non- } \\
\text { methanogenic } \\
\text { cells }\end{array}$} \\
\hline Coccoid type & $1.6 \mathrm{E}+10$ & 54.3 & 49.8 & $1.7 \mathrm{E}+10$ & 55.9 & 48.2 & $2.5 \mathrm{E}+10$ & 53.7 & 50.5 & $1.7 \mathrm{E}+10$ & 51.3 & 46.2 \\
\hline Rod type & $1.4 \mathrm{E}+10$ & 45.7 & 41.9 & $1.3 \mathrm{E}+10$ & 44.1 & 38.0 & $2.1 \mathrm{E}+10$ & 46.3 & 43.5 & $1.6 \mathrm{E}+10$ & 48.7 & 43.9 \\
\hline
\end{tabular}

${ }^{a}$ Not detected.

${ }^{\mathrm{b}}$ With $100 \%$ being all methanogenic cells detected.

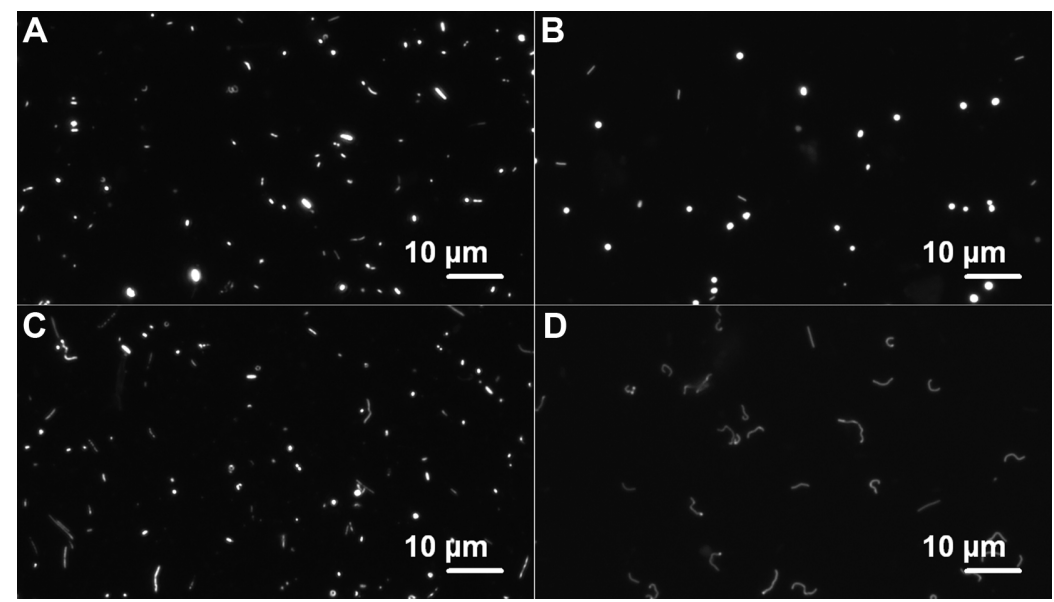

Fig. 3. Exemplary microscopic images of biogas-producing communities taken under 400-fold magnification.

A and C: Total cells stained with SYBR Green I (images were acquired from 1:60 diluted samples). B and D: Methanogens based on their autofluorescence (images were taken from 1:30 diluted samples). A and B: Samples from BGP2. C and D: Samples from BGP4.

under unfavorable conditions such as nutrient deficiency or substrate overload, resulting in stress conditions. Most of the coccoid methanogens (37\% of the $2.0 \%$ fraction) were between 1 and $2 \mu \mathrm{m}$ in length. The fraction of the rod-type methanogens (80\%) was between 1 and $6 \mu \mathrm{m}(94 \%$ of this size fraction). The methanogenic rods of BGP4 were slightly longer than those of the other BGPs.

The highest number of coccoid-type methanogens was found in BGP2 with $4.3 \mathrm{E}+9 / \mathrm{ml}$, whereas BGP4 revealed the lowest number of coccoid-type methanogens $(6.5 \mathrm{E}+8 / \mathrm{ml})$. The ratio of coccoid-type to rod-type methanogens was calculated to be 2.7 in BGP1, 7.1 in BGP2, 1.5 in BGP3, and 0.22 in BGP4 (Fig. 4). According to the knowledge available, coccoid-type methanogens such as Methanoculleus bourgensis belonging to the order Methanomicrobiales generally feature a cell diameter of 2 to $3 \mu \mathrm{m}$ (Fig. 4), whereas rod-type methanogens like Methanothermobacter thermautotrophicus belonging to the Methanobacteriales usually have a length of 


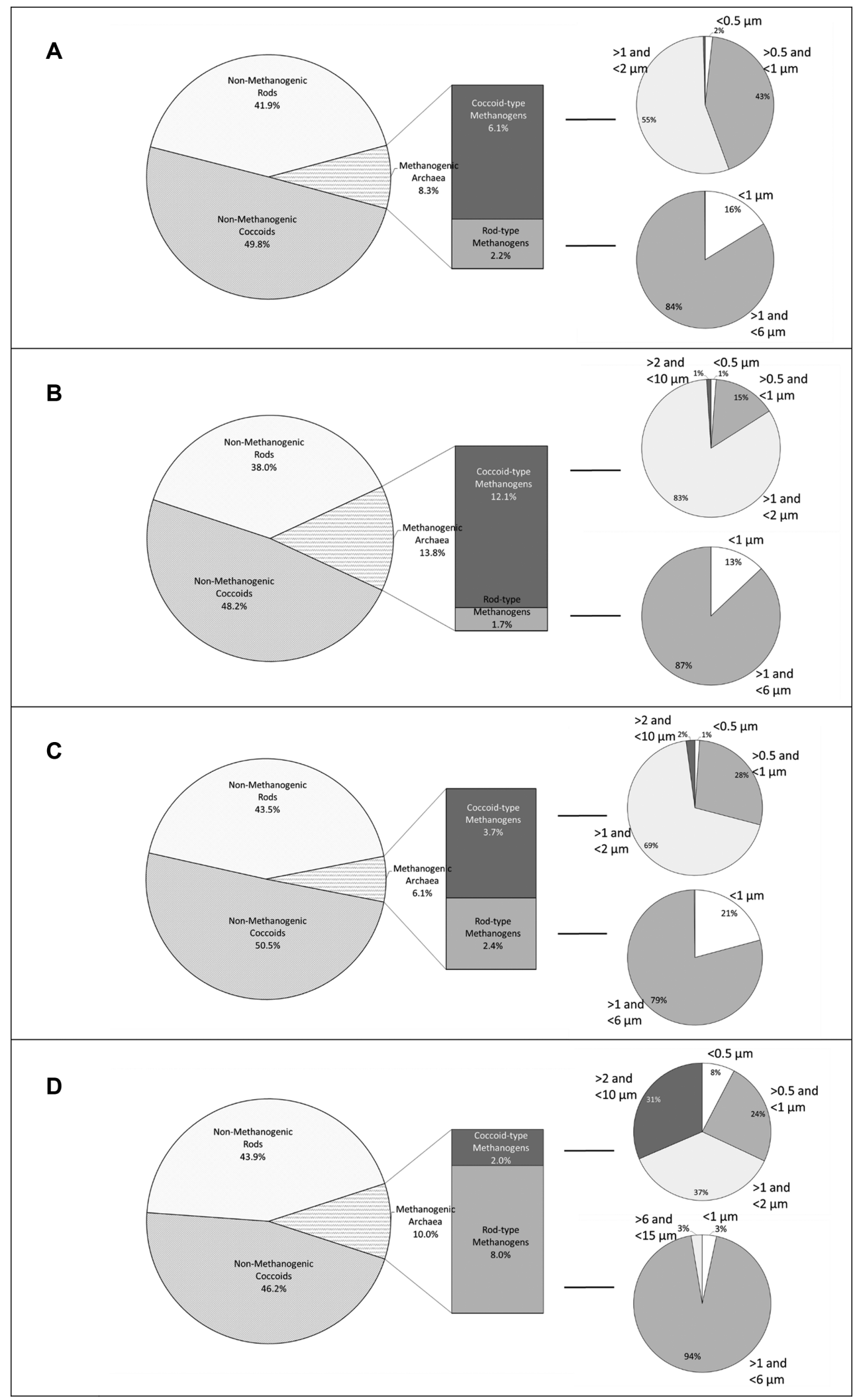

Fig. 4. Morphological classification of biogas-producing microbial communities in four anaerobic digesters. A: BGP1; B: BGP2; C: BGP3; and D: BGP4. 
2 to $6 \mu \mathrm{m}$ [37]. The coccoid-type methanogens have been shown to occur predominantly in mesophilic digesters, which generally produce a relatively high amount of biogas in comparison with sewage digesters [13, 14, 38, 39]. The observed high fluorescence intensity of $69 \%$ to $79 \%$ (Table 4) of the coccoid-type methanogens from BGP1 to 3 was assumed to be positively correlated with the biogas production rate measured in this study.

Regarding the order Methanosarcinales, multicellular packets characteristic for the family Methanosarcinaceae were not found in the four biogas plants. Straight sheathed filament-type methanogens that were supposed to belong to the family Methanosaetaceae were also not found (or were negligible at below 1\%) in all reactors. In regard to the nonmethanogenic cells, there were no significant microscopic differences among the four biogas plants. Based on morphological characteristics alone, it is not possible to differentiate Bacteria taxonomically.

\section{Discussion}

The structures of the methanogenic subcommunities residing in different agricultural biogas plants were analyzed by applying two different methods, HT $16 \mathrm{~S}$ rRNA gene amplicon sequencing and QMF, in order to evaluate the performance and resolution of both methods. Sequencing of $16 \mathrm{~S}$ rRNA gene amplicons provides distinct information on the bacterial part of the community that cannot be resolved by QMF. It was determined that morphological characteristics are not sufficiently diverse and discriminative enough to differentiate complex bacterial communities by QMF.

In the first instance, bacterial taxonomic profiles calculated from 16S rRNA gene sequences are in agreement with previous findings $[6,8,12,39]$. Among the bacterial members found in these anaerobic digester systems, those belonging to the classes Clostridia and Bacteroidetes dominated the biogas communities, followed by Proteobacteria, Bacilli, Flavobacteria, Spirochetes, and Erysipelotrichi. Depending on the process conditions, such as temperature and fed substrates, differences in the community profiles were identified [39-41]. For example, the bacterial phyla Actinobacteria, Deltaproteobacteria, and Spirochaetes were frequently found in mesophilic bioreactors [42], whereas members of the phylum Thermotogae (42\%) were observed to be a predominant taxon under thermophilic conditions [1, 43, 44]. Comparison of the four biogas communities analyzed in this study revealed that the genera Defluviitoga and Halocella were highly abundant in the thermophilic BGP4. Members of both genera were described to grow at high temperatures of up to $50^{\circ} \mathrm{C}$ for Halocella cellulolytica [45] and $70^{\circ} \mathrm{C}$ for Defluviitoga tunisiensis [46]. Additionally, these organisms use a variety of carbohydrates such as cellulose, cellobiose, xylan, and xylose for acetate, $\mathrm{CO}_{2}$, and $\mathrm{H}_{2}$ production, explaining their prevalence in thermophilic BGPs.

Analysis of the methanogenic subcommunities revealed that in the first instance, the results obtained by 16S rRNA gene amplicon sequencing and QMF are in agreement for BGP2 and BGP4. According to QMF, 87\% of the methanogens investigated in BGP2 were of the coccoid type in a size range of 1 and $2 \mu \mathrm{m}$, a typical size range of Methanomicrobiales [47]. Likewise, the dominance of Methanomicrobiaceae members $(92 \%)$ was also found by the $16 \mathrm{~S}$ rRNA gene sequencing approach in BGP2. Moreover, $80 \%$ of the methanogens in BGP4 appeared as rods assignable to the Methanobacteriales by QMF, which is in high agreement with the value of $86 \%$ for the genus Methanothermobacter identified by applying $16 \mathrm{~S}$ rRNA gene amplicon sequencing. The prevalence of the genus Methanoculleus (92\% of all archaeal sequences) in BGP2 raises the question of whether specific features may explain its competitiveness in fermenters utilizing only plant material as substrate for the digestion process. Westerholm et al. [48] recently described the isolation of Methanoculleus sp. in co-culture with the syntrophic acetate-oxidizing bacterium Syntrophaceticus schinkii from a mesophilic digester operating at a high ammonium concentration. Here, within the bacterial subcommunity of BGP2, the genus Syntrophaceticus (3\% of all sequences) was also found to be abundant, indicating that syntrophic acetate oxidation may play a role in methane production in this BGP. However, the biogas process of BGP2 was not characterized by high ammonium concentrations in comparison with the other mesophilic digesters analyzed. Moreover, the acetic acid production of BGP2 was $129 \mathrm{mg} / \mathrm{l}$, a comparatively low concentration (see Table 2). Apparently, a high turnover rate prohibits a high concentration of acetic acid. This might be the explanation for the abundance of Syntrophaceticus and Methanoculleus members within the BGP2 microbiome.

There were discrepancies between both methods regarding the quantification of members of the order Methanosarcinales comprising the genera Methanosarcina and Methanosaeta in BGP1 and BGP3. Methanosarcina species generally occur as multicellular aggregates (packets), which can be easily detected by microscopy due to their characteristic morphology. However, such packets were not observed in this study. This led to the consideration that the normal Methanosarcina shape was likely altered in the BGPs 
analyzed. Methanosarcina species may also grow as single cells (irregular coccoids) owing to increased osmolality [49-51], which is typical for agricultural BGPs featuring conductivities between 15.1 and $20.5 \mathrm{mS} / \mathrm{cm}$, corresponding to a content of 8.7 to $11.8 \mathrm{~g} \mathrm{KCl} / 1$ (Table 2). Older literature describing pure culture experiments showed that the occurrence of coccoid Methanosarcina cells is caused by the activity of a disaggregating enzyme [52]. Coccoid Methanosarcina mazei cells were isolated from an agricultural BGP for the first time by our group (data not shown here). However, the fluorescence intensity of these cells appeared to be relatively faint. Therefore, they might have been overlooked by fluorescence microscopy. Cells had a size of between 0.9 and $1.2 \mu \mathrm{m}$, which is exactly the size previously reported for M. mazei [47, 53]. Related observations were described in another study [54] investigating the microbial community of an anaerobic "waste-activated sludge" under thermophilic conditions, which featured a lower substrate concentration compared with a BGP. In this methanogenic community, the family Methanosarcinaceae was found to be dominant $(25-30 \%)$ and based on microscopic FISH analysis represented a conglomerate of loosely associated cells that appeared to be very small in size $(\leq 1 \mu \mathrm{m})$. However, no single coccoid cells were identified in sewage digester sludge like in the present study of the mesophilic BGPs 1 to 3. Corresponding mini-coccoid cells were also microscopically observed in all investigated BGPs.

Methanosaeta species can be differentiated by fluorescence microscopy only by their characteristic morphology (i.e., a sheathed filament structure), since the $\mathrm{F}_{420}$ fluorescence is too faint to be observed by fluorescence microscopy. A misinterpretation may arise, because only recently a rodlike Methanosaeta harundinacea was described [55]. It seems that the rod-like form of $M$. harundinaceae represents a very active culture in a high division mode [55]. However, in our study, a resolution at the species level could not be achieved. Nevertheless, the genus Methanosaeta was found in all investigated mesophilic BGPs. Methanosaeta members accounted for $67 \%$ of the methanogens in BGP1, $2 \%$ in BGP2, and $56 \%$ in BGP3. Fractions of $56 \%$ to $67 \%$ are astonishingly high for agricultural BGPs featuring standard performance and high substrate amounts (Tables 1 and 2) and were never observed before for these type of anaerobic digesters. Methanosaeta was not detected in the thermophilic BGP4, confirming results obtained for thermophilic laboratoryscale systems [37].

An advantage of QMF is the quantification of fluorescent (active) methanogens as well as their immediate classification exploiting morphological characteristics, which can be useful to confirm sequencing results based on the 16S rRNA gene. However, the resolution of QMF is low and impreciseness may occur owing to morphological modifications as response to specific environmental conditions. However, it provides a direct cell number as compared with more qualitative results of sequencing data. The parallel use of SYBR-Green stain avoids misinterpretation by inorganic particles. Regarding these issues, the sequencing approach is more precise and provides a resolution down to the nucleotide sequence level. Accordingly, almost the whole diversity of a given community can be captured by HT $16 \mathrm{~S}$ rRNA gene amplicon sequencing. However, this approach also has known shortcomings. Short Illumina read lengths do not cover the whole $16 \mathrm{~S}$ rRNA gene, which often limits taxonomic classification to the species level. The most critical issue of the $16 \mathrm{~S}$ rRNA gene sequencing approach is the choice of primers for amplification of the target fragment. PCR amplification is biased and may favor or discriminate specific taxa [23]. It is also important to note that with this technique, unknown taxa may be missed or underestimated. Considering these aspects, we recommend to use both methods for biogas microbial community profiling, since the quick QMF approach conveniently complements methods relying on HT DNA sequencing.

\section{Acknowledgments}

We have to thank Dipl. Biol. Nils Scharfenberg and Dr. Chem. Christian Rösner of the FSP "Biomassenutzung Hamburg" for their excellent chemical analyses. A very special thanks to Dr. Kyle J. Lauersen for English corrections that helped to improve the manuscript. The bioinformatics support of the BMBF-funded project "Bielefeld-Gießen Center for Microbial Bioinformatics BiGi (Grant No. 031A533)" within the German Network for Bioinformatics Infrastructure (de.NBI) is gratefully acknowledged. I.M. and D.W. acknowledge the receipt of a scholarship from the CLIB Graduate Cluster "Industrial Biotechnology" cofinanced by the Ministry of Innovation of North Rhine-Westphalia. The authors also acknowledge the German Federal Ministery of Food and Agriculture (BMEL) for financial support via the Fachagentur für Nachwachsende Rohstoffe e.V. (FNR) (joint research project Biogas-Core, FKZ 22017111 and BMP-III, FKZ 22404015).

\section{References}

1. Lebuhn M, Munk B, Effenberger M. 2014. Agricultural biogas production in Germany - from practice to microbiology 
basics. Energy Sustain. Soc. 4: 10.

2. Ridley CE, Clark CM, Leduc SD, Bierwagen BG, Lin BB, Mehl A, Tobias DA. 2012. Biofuels: network analysis of the literature reveals key environmental and economic unknowns. Environ. Sci. Technol. 46: 1309-1315.

3. Weiland P. 2010. Biogas production: current state and perspectives. Appl. Microbiol. Biotechnol. 85: 849-860.

4. Ali Shah F, Mahmood Q, Maroof Shah M, Pervez A, Ahmad Asad S. 2014. Microbial ecology of anaerobic digesters: the key players of anaerobiosis. Sci. World J. 2014: e183752.

5. Demirel B, Scherer PA. 2008. The roles of acetotrophic and hydrogenotrophic methanogens during anaerobic conversion of biomass to methane: a review. Rev. Environ. Sci. Biotechnol. 7: 173-190.

6. Stolze Y, Zakrzewski M, Maus I, Eikmeyer F, Jaenicke S, Rottmann N, et al. 2015. Comparative metagenomics of biogas-producing microbial communities from productionscale biogas plants operating under wet or dry fermentation conditions. Biotechnol. Biofuels 8: 8-14.

7. Krakat N, Schmidt S, Scherer PA. 2010. The mesophilic fermentation of renewable biomass - does hydraulic retention time regulate diversity of methanogens? Appl. Environ. Microbiol. 76: 6322-6326.

8. Jaenicke S, Ander C, Bekel T, Bisdorf R, Dröge $M$, Gartemann $\mathrm{KH}$, et al. 2011. Comparative and joint analysis of two metagenomic datasets from a biogas fermenter obtained by 454-pyrosequencing. PLoS One 6: e14519.

9. Kröber M, Bekel T, Diaz NN, Goesmann A, Jaenicke S, Krause L, et al. 2009. Phylogenetic characterization of a biogas plant microbial community integrating clone library 16S-rDNA sequences and metagenome sequence data obtained by 454-pyrosequencing. J. Biotechnol. 142: 38-49.

10. Theuerl S, Kohrs F, Benndorf D, Maus I, Wibberg D, Schlüter A, et al. 2015. Community shifts in a well-operating agricultural biogas plant: how process variations are handled by the microbiome. Appl. Microbiol. Biotechnol. 18: 7791-7803.

11. Eikmeyer FG, Rademacher A, Hanreich A, Hennig M, Jaenicke S, Maus I, et al. 2013. Detailed analysis of metagenome datasets obtained from biogas-producing microbial communities residing in biogas reactors does not indicate the presence of putative pathogenic microorganisms. Biotechnol. Biofuels 6: 49.

12. Zakrzewski M, Goesmann A, Jaenicke $S$, Jünemann $S$, Eikmeyer F, Szczepanowski R, et al. 2012. Profiling of the metabolically active community from a production-scale biogas plant by means of high-throughput metatranscriptome sequencing. J. Biotechnol. 158: 248-258.

13. Schlüter A, Bekel T, Diaz NN, Dondrup M, Eichenlaub R, Gartemann $\mathrm{KH}$, et al. 2008. The metagenome of a biogasproducing microbial community of a production-scale biogas plant fermenter analysed by the 454-pyrosequencing technology. J. Biotechnol. 136: 77-90.

14. Kim YS, Westerholm M, Scherer P. 2014. Dual investigation of methanogenic processes by quantitative PCR and quantitative microscopic fingerprinting (QMF). FEMS Microbiol. 360: 76-84.

15. Scherer PA, Neumann L, Kim Y. 2012. Schnellmethode zur biologischen Aktivitätsbestimmung in Biogasanlagen Quantitativer mikroskopischer Fingerabdruck (QMF), pp. 124-137. In IHK (ed.). Biogas Potenziale: Erkennen, Erforschen, Erwirtschaften. Bornimer Agrartechnische Berichte, PotsdamBornim, Germany.

16. Maus I, Cibis KG, Bremges A, Stolze Y, Wibberg D, Tomazetto D, et al. 2016. Genomic characterization of Defluviitoga tunisiensis L3, a key hydrolytic bacterium in a thermophilic biogas plant and its abundance as determined by metagenome fragment recruitment. J. Biotechnol. 232: 50-60.

17. Stolze $Y$, Bremges A, Rumming M, Henke C, Maus I, Pühler $A$, et al. 2016. Identification and genome reconstruction of distinct taxa in microbiomes from four different productionscale biogas plants. Biotechnol. Biofuels 9: 156.

18. Raposo F, Borja R, Mumme J, Orupold K, Esteves S, Noguerol-Arias J, et al. 2013. First international comparative study of volatile fatty acids in aqueous samples by chromatographic techniques: evaluating sources of error. Trends Anal. Chem. 51: 127-144.

19. VDI4630. 2006. Fermentation of organic materials: characterization of the substrate, sampling, collection of material data, fermentation tests. Verein Deutscher Ingenieure, Düsseldorf, ICS13.030.30;27.190. Available from http://www.vdi.eu/ uploads/tx_vdirili/pdf/9703240.pdf. Accessed March 10, 2016.

20. Hansen KH, Angelidaki I, Ahring BK. 1998. Anaerobic digestion of swine manure: inhibition by ammonia. Water Res. 32: 5-12.

21. Scherer PA. 2007. Operational analytics of biogas plants to improve efficiency and to ensure process stability, pp. 77-84. In IBBK (ed.). Progress in Biogas. Kirchberg, Germany.

22. KTBL. 2013. Faustzahlen Biogas. 3. Auflage. Kuratorium für Technik und Bauwesen in der Landwirtschaft eV (KTBL) \& Fachagentur Nachwachsender Rohstoffe (FNR), Darmstadt, Germany.

23. Takahashi S, Tomita J, Nishioka K, Hisada T, Nishijima M. 2014. Development of a prokaryotic universal primer for simultaneous analysis of Bacteria and Archaea using nextgeneration sequencing. PLoS One 9: e105592.

24. Magoč T, Salzberg SL. 2011. FLASH: fast length adjustment of short reads to improve genome assemblies. Bioinformatics 27: 2957-2963.

25. Edgar RC. 2010. Search and clustering of magnitude faster than BLAST. Bioinformatics 26: 2460-2461.

26. Edgar RC. 2013. UPARSE: highly accurate OTU sequences from microbial amplicon reads. Nat. Methods 10: 996-998.

27. Wang Q, Garrity GM, Tiedje JM, Cole JR. 2007. Naive Bayesian classifier for rapid assignment of rRNA sequences into the new bacterial taxonomy. Appl. Environ. Microbiol. 73: 5261-5267.

28. Liebe S, Wibberg D, Winkler A, Pühler A, Schlüter A, Varrelmann M. 2016. Taxonomic analysis of the microbial 
community in stored sugar beets using high-throughput sequencing of different marker genes. FEMS Microbiol Ecol. 92. DOI: $10.1093 /$ femsec/fiw004.

29. Maus I, Cibis KG, Wibberg D, Winkler A, Stolze Y, König $\mathrm{H}$, et al. 2015. Complete genome sequence of the strain Defluviitoga tunisiensis L3, isolated from a thermophilic, production-scale biogas plant. J. Biotechnol. 203: 17-18.

30. Metsalu T, Vilo J. 2015. ClustVis: a web tool for visualizing clustering of multivariate data using principal component analysis and heatmap. Nucleic Acids Res. 43: W566-W570.

31. Paulson JN, Stine OC, Bravo HC, Pop M. 2013. Differential abundance analysis for microbial marker-gene surveys. Nat. Methods 10: 1200-1202.

32. Nielsen HB, Uellendahlm H, Ahring BK. 2007. Regulation and optimization of the biogas process: propionate as a key parameter. Biomass Bioenerg. 31: 820-830.

33. Li H. 2015. GitHub Repository. Toolkit for processing sequences in FASTA/Q formats. Available from https:// github.com/lh3/seqtk. Accessed August 28, 2016.

34. Itoh T, Iino T. 2013. Phylogeny and biotechnological features of thermophiles, pp. 249-270. In Satyanarayana T, Littlechild J, Kawarabayasi Y. (eds.). Thermophilic Microbes in Environmental and Industrial Biotechnology. Springer, Netherlands.

35. Mirmohammadsadeghi H, Abedi D, Mohmoudpour HR, Akbari V. 2013. Comparison of five methods for extraction of genomic DNA from a marine Archaea, Pyrococcus furiosus. Pak. J. Med. Sci. 29: 390-394.

36. Visweswaran GR, Dijkstra BW, Kok J. 2010. Two major archaeal pseudomurein endoisopeptidases: PeiW and PeiP. Archaea 2010: 480492.

37. Krakat N, Westphal A, Schmidt S, Scherer P. 2010. Anaerobic digestion of renewable biomass - thermophilic temperature governs population dynamics of methanogens. Appl. Environ. Microbiol. 76: 1842-1850.

38. Nettmann E, Bergmann I, Pramschüfer S, Mundt K, Plogsties V, Herrmann C, Klocke M. 2010. Polyphasic analyses of methanogenic archaeal communities in agricultural biogas plants. Appl. Environ. Microbiol. 76: 2540-2548.

39. Wirth R, Kovács E, Maróti G, Bagi Z, Rákhely G, Kovács KL. 2012. Characterization of a biogas-producing microbial community by short-read next generation DNA sequencing. Biotechnol. Biofuels 5: 41-57.

40. Ziembińska-Buczyńska A, Banach A, Bacza T, Pieczykolan M. 2014. Diversity and variability of methanogens during the shift from mesophilic to thermophilic conditions while biogas production. World J. Microbiol. Biotechnol. 30: 30473053.

41. Lee SH, Kang HJ, Lee YH, Lee TJ, Han K, Choi Y, Park HD. 2012. Monitoring bacterial community structure and variability in time scale in full-scale anaerobic digesters. J. Environ. Monit. 14: 1893-1905.

42. Levén L, Eriksson AR, Schnürer A. 2007. Effect of process temperature on bacterial and archaeal communities in two methanogenic bioreactors treating organic household waste. FEMS Microbiol. Ecol. 59: 683-693.

43. Ritari J, Koskinen K, Hultman J, Kurola JM, Kymäläinen M, Romantschuk M, et al. 2012. Molecular analysis of mesoand thermophilic microbiota associated with anaerobic biowaste degradation. BMC Microbiol. 12: 121.

44. Maus I, Koeck DE, Cibis KG, Hahnke S, Kim YS, Langer T, et al. 2016. Unraveling the microbiome of a thermophilic biogas plant by metagenome and metatranscriptome analysis complemented by characterization of bacterial and archaeal isolates. Biotechnol. Biofuels 9: 171.

45. Simankova MV, Chernych NA, Osipov GA, Zavarzin GA. 1993. Halocella cellulolytica gen. nov., sp. nov., a new obligately anaerobic, halophilic, cellulolytic bacterium. Syst. Appl. Microbiol. 16: 385-389.

46. Ben Hania W, Godbane R, Postec A, Hamdi M, Ollivier B, Fardeau ML. 2012. Defluviitoga tunisiensis gen. nov., sp. nov., a thermophilic bacterium isolated from a mesothermic and anaerobic whey digester. Int. J. Syst. Evol. Microbiol. 62: 1377-1382.

47. Whitman WB, Boone DR, Koga Y, Keswani J. 2001. Euryarchaeota phy. nov., pp. 211-294. In Boone DR, Castenholz RW, Garrity GM (eds.). Bergey's Manual of Systematic Bacteriology. Springer, New York.

48. Westerholm M, Roos S, Schnürer A. 2010. Syntrophaceticus schinkii gen. nov., sp. nov., an anaerobic, syntrophic acetateoxidizing bacterium isolated from a mesophilic anaerobic filter. FEMS Microbiol. Lett. 309: 100-104.

49. Ahring BK, Alatriste-Mondragon F, Westermann P, Mah RA. 1991. Effects of cations on Methanosarcina thermophile TM-1 growing on moderate concentration of acetate: production of single cells. Appl. Microbiol. Biotechnol. 35: 686-689.

50. Sowers KR, Boone J, Gunsalus RP. 1993. Disaggregation of Methanosarcina spp. and growth as single cells at elevated osmolarity. Appl. Environ. Microbiol. 59: 3832-3839.

51. Sowers K, Gunsalus RP. 1988. Adaption for growth at various saline concentrations by the archaebacterium Methanosarcina thermophile. J. Bacteriol 170: 998-1002.

52. Liu Y, Boone DR, Sleat R, Mah RA. 1985. Methanosarcina mazei LYC, a new methanogenic isolate which produces a disaggregating enzyme. Appl. Environ. Microbiol. 49: 608-613.

53. Boone DR, Whitman WB, Rouviere P. 1993. Diversity and taxonomy of methanogens, pp. 35-80. In Ferry JG (ed.). Methanogenesis. Chapman \& Hall Inc., New York.

54. Ho DP, Jensen PD, Batstone DJ. 2013. Methanosarcinaceae and acetate-oxidizing pathways dominate in high-rate thermophilic anaerobic digestion of waste-activated sludge. Appl. Environ. Microbiol. 79: 6491-6500.

55. Zhou L, Yu H, Ai G, Zhang B, Hu S, Dong X. 2014. Transcriptomic and physiological insights into the robustness of long filamentous cells of Methanosaeta harundinacea, prevalent in upflow anaerobic sludge blanket granules. Appl. Environ. Microbiol. 81: 831-839. 